Research Article

\title{
Research on Fatigue Model of Semi-Rigid Base Asphalt Pavement before and after Polymer Grouting
}

\author{
Bei Zhang $(\mathbb{D}$, Xu Zhang, Yanhui Zhong $(\mathbb{D}$, Xiaolong Li $\mathbb{D}$, Meimei Hao $\mathbb{D}$, Xianwei Sang, \\ Xiaoliang Wang, and Jianyang Liu
}

College of Water Conservancy and Engineering, Zhengzhou University, Zhengzhou 450001, China

Correspondence should be addressed to Yanhui Zhong; zhong_yanhui@163.com and

Xiaolong Li; wennuandeshang@hotmail.com

Received 9 December 2020; Revised 26 January 2021; Accepted 2 February 2021; Published 22 February 2021

Academic Editor: Di Wang

Copyright (c) 2021 Bei Zhang et al. This is an open access article distributed under the Creative Commons Attribution License, which permits unrestricted use, distribution, and reproduction in any medium, provided the original work is properly cited.

To improve the service life of a semirigid base asphalt pavement and prolong its service cycle, it is imperative to conduct long-term performance research before and after pavement disease repair. This study proposes a fatigue damage model for pavement and polymer materials and uses the finite element method to establish a three-dimensional numerical model of a semirigid base asphalt pavement structure. Moreover, it compares and analyzes the mechanical response and fatigue damage of this pavement before and after polymer repair. The evolution law is verified by indoor fatigue tests. The results show that, under a standard load of $0.7 \mathrm{MPa}$, the vertical displacement and the Mises stress of the vacant position after the polymer repair are reduced by $61 \%$ and $69 \%$, respectively. Under a cyclic load of $1.2 \mathrm{MPa}$, the number of load actions increases from 500,000 to more than 5 million, and the fatigue damage factor of the polymer is reduced by $29 \%$. With the increase in the number of fatigue test loads, the cumulative evolution trend of the fatigue damage is basically consistent with the results of the numerical simulation, which verifies the rationality of the numerical model. This research is relevant for providing a reference for extending the service life of expressways and improving the technical level of expressway maintenance.

\section{Introduction}

In recent years, highway construction in China has developed rapidly, and the scale and number of constructions have increased swiftly. In 2019, the total mileage of highways reached 5 million $\mathrm{km}$, of which $143,000 \mathrm{~km}$ corresponded to expressways. Semirigid base pavement structures are the most extensively used ones in expressways owing to their high stiffness and high stability [1]. Under the cyclic effect of vehicle load and the rapid increase in traffic volume, a semirigid base layer undergoes a certain degree of plastic deformation, and some voids or even vacancies form at the bottom of the base layer, causing fatigue damage. Thus, in turn, results in the road structure no longer serving as a continuous and uniform support structure, which severely affects opening an expressway to traffic and its normal use, thereby threatening the healthy development of the society and the economy [2].
Numerous scholars have conducted studies on the fatigue characteristics of semirigid base asphalt pavement structures. In 2014, Maitra et al. established a numerical model based on fictitious crack and stress degradation approaches to theoretically study the internal crack growth and fatigue characteristics of a concrete pavement under cyclic loading [3]. In 2016, Hu et al. used digital image processing to detect the microstructure of asphalt mixtures, studied and analyzed the changes in their internal structure morphology, and obtained the relationship between the microstructure and the fatigue damage [4]. In 2018, Cheng et al. studied the fatigue characteristics of in-service cold central-plant recycling (CCPR) and hot mix asphalt (HMA) mixtures by indirect tensile fatigue tests and obtained their fatigue failure characteristics and fatigue life. Moreover, they proposed a method to calculate CCPR based on the fatigue test results, on-site traffic load, and HMA mixture displacement factor method [5]. In 2018, Barman et al. used the fatigue index $f_{i}$ to 
characterize the fatigue resistance of asphalt mixtures and tested the fatigue resistance of five different types using the indirect tension test data [6]. In 2019, Lv et al. conducted unconfined compressive strength, indirect tensile strength, and four-point bending strength tests on cement-stabilized crushed stone specimens under various loading rates to obtain the fatigue test stress ratio related to the loading rate and solve various problems. There exist uncertainty and nonuniqueness of fatigue characteristics in the single-load mode [7]. In 2019, Zhang et al. introduced loading frequency into the classic Chaboche damage evolution model, conducted theoretical analysis and laboratory tests, and established a new damage evolution model [8]. In 2020, Wei et al. studied the effects of frequency, load displacement, asphalt aggregate ratio, and aging degree on the fatigue performance and disturbance changes of large stone asphalt mixtures based on the viscoelastic continuum damage model method [9]. In summary, it can be seen that relatively there are many studies on the fatigue characteristics of road materials using traditional fatigue test methods; however, they have disadvantages, such as long test cycles, high capital investment, and lack of theoretical basis.

The traditional methods for repairing semirigid base asphalt pavement diseases include excavation and reconstruction, paving, grouting, and cement-based grouting repair technology. However, these methods have long construction and maintenance times; consume substantial manpower, material resources, and financial resources; and severely affect traffic [10]. In recent years, polymer grouting repair technology has been an emerging nonexcavation repair technology. It has been extensively used in the treatment of many hidden road diseases in China and achieved good results [11]. Shi et al. studied the compressive strength of polymer grouting materials having different densities and at different temperatures by uniaxial compression tests [12]. Liu et al. studied the compressive mechanical properties of polyurethane polymer grouting materials of different densities, and the results showed that polyurethane polymer grouting materials of low densities possess elastoplastic characteristics [13]. Bezazi and Scarpa comparatively analyzed the cyclic load tensile behaviors of conventional and expanded thermoplastic polyurethane polymers and studied the relationship between the decrease in their stiffness and the accumulation of energy dissipation and the number of cycles [14]. Pulungan et al. proposed a viscoelastic-viscoplastic damage model for polypropylenebased polymers, which was verified by three-point bending tests conducted at different loading speeds [15]. From the above studies, it can be seen that polymer materials have good mechanical properties and fatigue resistance.

In summary, although polymer grouting repair technology has been widely used in the treatment of many road diseases in my country and has achieved good repair results. However, there are relatively few studies on the long-term service performance of polymer grouting repaired roads, and the evolution of fatigue damage of the pavement structure after polymer grouting repair is not clear. Therefore, in this study, polymer grouting technology is used to repair the vacancy disease of a semirigid base asphalt pavement, and a fatigue damage model suitable for semirigid base materials and polymer grouting materials is proposed. A finite element software is used to modify the pavement structure before and after the repair. Mechanical response analysis, the repair effect of the polymer grouting to repair the void disease of the semirigid base, and the evolution law of the fatigue damage were studied, and the model was verified by indoor fatigue tests. This study has theoretical reference significance for the prediction of the remaining life of a semirigid base asphalt pavement and the repair of hollow semirigid base asphalt pavements by polymer grouting.

\section{Material Fatigue Damage Model}

2.1. Two-Stage Fatigue Damage Model of Pavement Structure Materials. In this study, based on the simplified Chaboche nonlinear fatigue damage model, the evolution process of the fatigue damage of semirigid base asphalt pavement structural materials is corrected. Moreover, a two-stage fatigue damage model suitable for the rapid and steady growth of pavement structural material damage variables is established to study the evolution law of structural fatigue damage of a semirigid base asphalt pavement.

(1) Cumulative law of damage evolution in Chaboche nonlinear fatigue damage model

The simplified Chaboche nonlinear fatigue damage model is [16]

$$
\frac{\mathrm{d} D}{\mathrm{~d} N}=a\left[\frac{\sigma}{(1-D)}\right]^{p},
$$

where $a$ and $p$ are the characteristic damage parameters of the material, $N$ is the number of cyclic loading, $D$ is the current damage, and $\sigma$ is the load stress during the cyclic loading.

The fatigue damage model can describe the phenomena of different loading sequences and different damage conditions when multilevel loads are applied sequentially, which is highly convenient in finite element calculation. The damage evolution and accumulation rules of the simplified Chaboche nonlinear fatigue damage model are listed in Table 1.

It can be seen from Table 1 that the initial damage of the material is assumed to be $D_{0}=0$, the stress during the first cyclic loading is $\sigma$, and the damage caused by the first cyclic loading is $D_{1}=a \sigma^{p}$. Assuming that the cyclic stress remains unchanged, the damage caused by the second cyclic loading is $D_{2}=a\left(\sigma /\left(1-D_{1}\right)\right)^{p}$. Thus, the damage caused by the nth cycle loading is $D_{n}=a\left(\sigma /\left(1-D_{n-1}\right)\right)^{p}$, and the total damage caused by the $n$th cycle is $D_{M}=D_{1}+D_{2}+\cdots+D_{n}=a \sigma_{1}^{p}$ $+a\left(\sigma_{2} /\left(1-D_{1}\right)\right)^{p}+\cdots+a\left(\sigma_{n} /\left(1-D_{n-1}\right)\right)^{p}$.

(2) Chaboche nonlinear fatigue damage model correction

The destruction of pavement structure materials is divided into two stages: crack formation and 
TABLE 1: Simplified Chaboche nonlinear fatigue damage model damage evolution and accumulation law.

\begin{tabular}{lccc}
\hline$N$ & $\sigma$ & $D_{N}$ & $D_{M}$ \\
\hline 0 & 0 & 0 & 0 \\
1 & $\sigma_{1}$ & $a \sigma_{1}^{p}$ & $a \sigma_{1}^{p}$ \\
2 & $\sigma_{2}$ & $a\left(\sigma_{2} /\left(1-D_{1}\right)\right)^{p}$ & $a \sigma_{1}^{p}+a\left(\sigma_{2} /\left(1-D_{1}\right)\right)^{p}$ \\
$\cdots$ & $\cdots$ & $\cdots$ & $\cdots$ \\
$n$ & $\sigma_{n}$ & $a\left(\sigma_{n} /\left(1-D_{n-1}\right)\right)^{p}$ & $a \sigma_{1}^{p}+a\left(\sigma_{2} /\left(1-D_{1}\right)\right)^{p}+\cdots+a\left(\sigma_{n} /\left(1-D_{n-1}\right)\right)^{p}$ \\
\hline
\end{tabular}

macrocrack propagation. When the fatigue damage reaches the critical value, DC, cracks are formed and macroscopic cracks begin to grow. In this study, the critical value of the fatigue damage $\mathrm{DC}=0.5$ [17]. The semirigid base material is brittle, and the fatigue life of the macroscopic crack propagation stage is relatively short. Therefore, this study mainly examines the crack formation stage and approximates the fatigue life of the used pavement structure material to the fatigue life of the crack formation stage.

In this study, the elastic modulus loss is used to define the material damage variable $D$ as follows:

$$
D=1-\frac{\widetilde{E}}{E}
$$

where $\widetilde{E}$ is the modulus of the damaged state and $E$ is the modulus of the nondestructive state.

The simplified Chaboche nonlinear fatigue damage model has a certain impact on the simulation analysis of the pavement structure damage field and the fatigue damage evolution process, and the model needs to be modified to a certain extent. From the simplified Chaboche nonlinear fatigue damage model, it can be found that, in the controlled stress fatigue test method, the damage accumulation rate is determined by $1 /(1-D)$. In this study, it is revised to $1 /(1-D)^{\alpha}$, so that, by changing the size of $\alpha$, the material damage accumulation rate is changed. The revised fatigue damage model is

$$
\frac{\mathrm{d} D}{\mathrm{~d} N}=\left\{\begin{array}{l}
a\left[\frac{\sigma}{(1-D)^{\alpha_{1}}}\right]^{p} \quad\left(0 \leq D \leq D_{m}\right) \\
a\left[\frac{\sigma}{(1-D)^{\alpha_{2}}}\right]^{p} \quad\left(D_{m} \leq D \leq D_{c}\right)
\end{array}\right.
$$

where $D_{m}$ is 0.35 and $D_{c}$ is 0.5 .

(3) Two-stage fatigue damage model parameters

(a) Fatigue damage model material characteristic parameters $a$ and $p$

In this study, the pavement structure is simplified as a single beam specimen. Moreover, the beam specimen is analyzed and deduced under a fixed load based on the damage evolution characteristics of a two-stage fatigue damage model and the material classic fatigue life formula to determine model parameters $a$ and $p$ [18-20].
(1) The empirical formula for the fatigue life of the pavement structure trabecular material under the controlled stress mode is

$$
N_{f}=A \sigma^{-B}
$$

(2) Material characteristic parameters $a$ and $p$ are calculated assuming that $\alpha=1$. Specifically,

$$
\frac{\mathrm{d} D}{\mathrm{~d} N}=a\left[\frac{\sigma}{(1-D)}\right]^{p} .
$$

(3) The constitutive formula of the damaged material can be obtained from equation (2) as follows:

$$
\sigma=E(1-D) \mathcal{\varepsilon}
$$

(4) The relationship between the deformation and displacement of the static trabeculae can be derived as follows:

$$
\begin{aligned}
\varepsilon & =\frac{y}{\rho}, \\
\sigma & =\frac{E(1-D) y}{\rho}, \\
\frac{\mathrm{d} D}{\mathrm{~d} N} & =a E^{P} \varepsilon^{P},
\end{aligned}
$$

where $\rho$ is the radius of curvature of the beam, $\varepsilon$ is the plane section strain of the beam, and $y$ is the distance from a point on the beam section to the neutral axis of the section.

(5) Point $C$ represents the point at the bottom of the beam on the cross section of the trabeculae:

$$
\begin{gathered}
\varepsilon_{c}=\frac{y_{c}}{\rho}, \\
\frac{\mathrm{d} D_{c}}{\mathrm{~d} N}=a E^{P} \varepsilon_{c}^{P}, \\
\frac{\mathrm{d} D}{\mathrm{~d} D_{c}}=\frac{\varepsilon^{P}}{\varepsilon_{c}^{P}}=\frac{y^{P}}{y_{c}^{P}} .
\end{gathered}
$$

(6) Assuming that the position of the neutral axis does not change with the damage process, integrating equation (8) yields 


$$
\begin{aligned}
D & =\frac{y^{P}}{y_{c}^{P}} D_{c}, \\
\sigma & =\frac{E\left(1-\left(y^{P} / y_{c}^{P}\right) D_{c}\right) y}{\rho} .
\end{aligned}
$$

(7) The bending moment balance formula on the cross section is

$$
\begin{aligned}
& M=\int y \sigma \mathrm{d} A, \\
& M=\int \frac{E\left(1-\left(y^{P} / y_{c}^{P}\right) D_{c}\right) y^{2}}{\rho \mathrm{d} A} .
\end{aligned}
$$

(8) If $\bar{I}=\int y^{2}(1-D) \mathrm{d} A=\int y^{2}\left(1-\left(y^{P} / y_{c}^{P}\right) D_{c}\right) \mathrm{d} A$ represents the moment of inertia after the section is damaged, then

$$
\frac{1}{\rho}=\frac{M}{E \vec{I}}
$$

(9) When the trabeculae are not damaged,

$$
\begin{aligned}
\sigma_{0} & =\frac{M y}{I_{0}}, \quad I_{0}=\int y^{2} \mathrm{~d} A, \\
D & =\frac{p+3}{p}\left\{1-\left[1-a N\left(\sigma_{0}\right)^{p} \frac{3(p+1)}{p+3}\right]^{1 /(p+1)}\right\} .
\end{aligned}
$$

(10) Considering the initial stress at point $C$ as $\sigma_{c}$,

$D_{c}=\frac{p+3}{p}\left\{1-\left[1-a N\left(\sigma_{c}\right) \frac{p(p+1)}{p+3}\right]^{1 /(p+1)}\right\}$.

When $D_{c}=0.5$, the corresponding number of cycles, $N_{c r}$, is the fatigue crack formation life.

$N_{c r}=\frac{p+3}{3 a(p+1)(0.5)^{p}}\left[1-\left(\frac{p}{p+3}\right)^{p+1}\right]\left(\sigma_{c}\right)^{-p}$.

Comparing equation (1) with the empirical formula of fatigue life yields

$$
\begin{aligned}
& A=\frac{p+3}{3 a(p+1)(0.5)^{p}}\left[1-\left(\frac{p}{p+3}\right)^{p+1}\right], \\
& B=p .
\end{aligned}
$$

From equations (15) and (16), it can be seen that determining the classic fatigue life equation of the trabecular material can yield the two-stage fatigue damage model parameters of $a$ and $p$.

Based on the parameter determination method used in this study and the empirical formula of the fatigue life of different pavement structure materials, parameters $a$ and $p$ of different pavement structure materials can be obtained, which are listed in Table 2.

(b) Fatigue damage model correction parameter $\alpha$ The accumulation rate of the material fatigue damage is determined by the current stress $\sigma$ and $1 /(1-D)^{\alpha}$. When the stress is a fixed value, the larger the value of $1 /(1-D)^{\alpha}$, the higher the accumulation rate of the fatigue damage; the smaller the value of $1 /(1-D)^{\alpha}$, the lower the accumulation rate of the fatigue damage. This study defines $1 /(1-D)^{\alpha}$ as the sensitivity coefficient of the fatigue damage rate to the current stress.

(1) When $\alpha>1$, the sensitivity coefficient of the fatigue damage rate to the stress increases, which increases the damage field gradient. When $\alpha<1$, the sensitivity coefficient of the fatigue damage rate to the stress decreases, which reduces the damage field gradient to correct the damage model effect. Therefore, $\alpha<1$ during the model revision process.

(2) This study uses a trial algorithm to determine the specific values of the two-stage fatigue damage model parameters: $\alpha_{1}$ and $\alpha_{2}$. To this end, first $\alpha_{1}$ and $\alpha_{2}$ are assumed, and they are combined with parameters $a$ and $p$. Subsequently numerical simulations are conducted, and the simulation results are compared with the test data. If the results are close, then the hypothetical values of $\alpha_{1}$ and $\alpha_{2}$ are valid; otherwise, they are reassumed. Following many trial calculations, this study yields $\alpha_{1}=0.4$ and $\alpha_{2}=0.2$.

(4) Two-stage fatigue damage model verification

Substituting the model parameters to obtain the twostage fatigue damage model of a semirigid base asphalt pavement structure material can be expressed as

$$
\frac{\mathrm{d} D}{\mathrm{~d} N}= \begin{cases}a\left[\frac{\sigma}{(1-D)^{0.4}}\right]^{p} & \left(0 \leq D \leq D_{m}\right), \\ a\left[\frac{\sigma}{(1-D)^{0.2}}\right]^{p} & \left(D_{m} \leq D \leq D_{c}\right) .\end{cases}
$$

In this study, a two-dimensional finite element simulation of a typical semirigid base asphalt pavement structure material cement-stabilized gravel is conducted, and the simulation results of the fatigue damage evolution are compared with those of the indoor fatigue tests, as shown in Figure 1.

It can be seen from Figure 1 that the finite element simulation results of the cement-stabilized gravel material are in good agreement with the test results. This proves that the two-stage fatigue damage model used in this study can 
TABle 2: Summary of material damage parameters $a$ and $p$ for different pavement structures.

\begin{tabular}{lcc}
\hline Pavement structure materials & $a$ & $p$ \\
\hline SMA-13 & $2.81 e-3$ & 4 \\
AC-20 & $2.81 e-3$ & 4 \\
AC-25 & $2.81 e-3$ & 4 \\
Cement-stabilized macadam & $1.36 e+4$ & 2.02 \\
Cement-stabilized gravel & $9.52 e+7$ & 2.02 \\
\hline
\end{tabular}

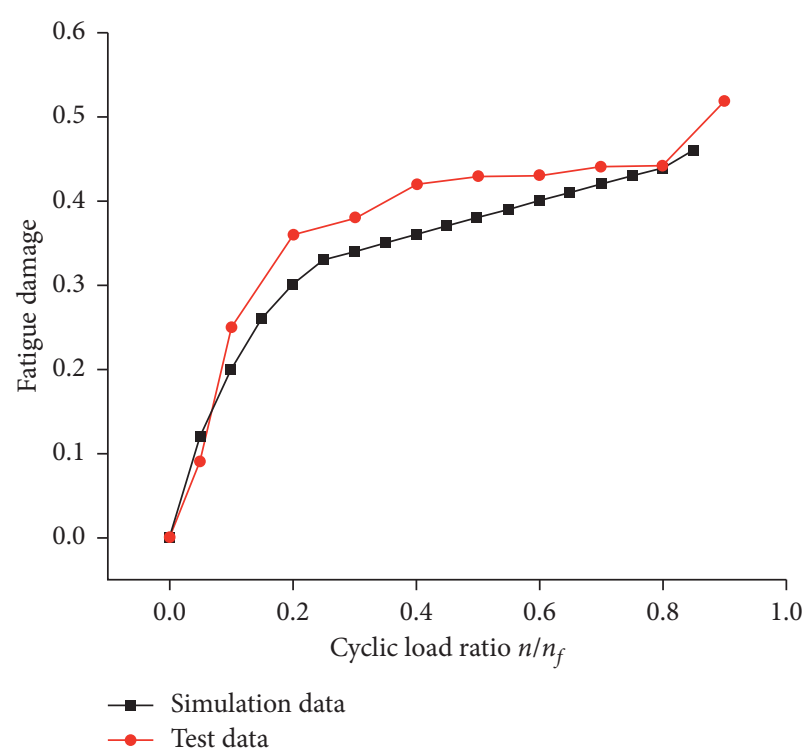

Figure 1: Comparison of results of fatigue damage accumulation curves of cement-stabilized gravel.

effectively predict the fatigue damage evolution process of semirigid base materials.

2.2. D-N Fatigue Damage Model of Polymer Grouting Material. Compared with polymer materials, the stress generated by a road surface under a traffic load is low. According to the phenomenological theory, this study adopts a 0.7 stress ratio level $D-N$ fatigue damage model as the fatigue damage model of the polymer grouting materials.

As per [21], the microdamage evolution of same-density polymer material specimens under various stress levels can be divided into three stages. This study selects a $0.3 \mathrm{~g} / \mathrm{cm}^{3}$ polymer material to analyze the measured data of the cyclic compression fatigue test and obtains the fatigue damage equation for its each stage when the stress ratio is 0.7, as shown in Figure 2.

From the regression analysis, the $D-N$ fatigue damage evolution model of the above-mentioned polymer grouting material can be obtained as

$$
D= \begin{cases}-0.03207 \times e^{(-(N / 29.7877))}+0.03192 & (N<100), \\ -0.01616 \times e^{(-(N / 2450.51))}+0.04014 & (100<N<10000), \\ 0.03474 \times e^{(-(N / 173249.44))}+0.00838 & (N>10000) .\end{cases}
$$

The three-stage correlation coefficients, $R^{2}$, are 0.9185 , 0.8249 , and 0.7607 , respectively. It can be seen that the fitting equations of the first two stages are highly correlated. Owing to the cyclic hardening of the polymer material in the third stage of damage evolution, the fatigue damage value is reduced to a certain extent. This study does not consider the third stage of damage evolution [22].

Therefore, the polymer $D-N$ fatigue damage model used in expressway grouting repair is

$$
D= \begin{cases}-0.03207 \times e^{(-(N / 29.7877))}+0.03192 & (N<100), \\ a\left(-0.01616 \times e^{(-(N / 2450.51))}+0.04014\right) & (100<N),\end{cases}
$$

where $a$ is 0.626 to ensure the continuity of the damage curve.

\section{Research on Fatigue Characteristics of Semirigid Base Pavement}

3.1. Numerical Simulation Research. In the engineering field, in the process of studying the fatigue characteristics of the actual pavement structure, the method of finite element numerical analysis is usually used to realize it. In this section, based on the ABAQUS finite element software, the user material subroutine of the damaged material is written, the damage variable is introduced into the constitutive equation of the damaged material, and the fatigue characteristics of the pavement structure under the traffic load are numerically simulated and analyzed.

(1) Basic assumptions

This study makes the following assumptions about the pavement structure model based on the theory of a multilayer elastic system of asphalt pavements [23]:

(1) Each structural layer is composed of isotropic materials, which are continuous and uniform elastic layered systems.

(2) The soil foundation is infinite in the horizontal and vertical directions, and the other structural layers are infinite in the horizontal direction.

(3) Only the vertical displacement and stress are continuous between the layers, without considering frictional resistance.

(2) Model description

In this study, considering the symmetry of the pavement structure and load, the fatigue damage calculation time is extremely long [24]. A 1/2 pavement model is selected for the analysis. The size of the model is length $\times$ width $\times$ height $=6 \mathrm{~m} \times 6 \mathrm{~m} \times 3 \mathrm{~m}$. The pavement structure consists of six parts: SMA-13, AC-20, AC-25, cement-stabilized macadam base, cementstabilized gravel base, and soil base, as shown in Figure 3. 

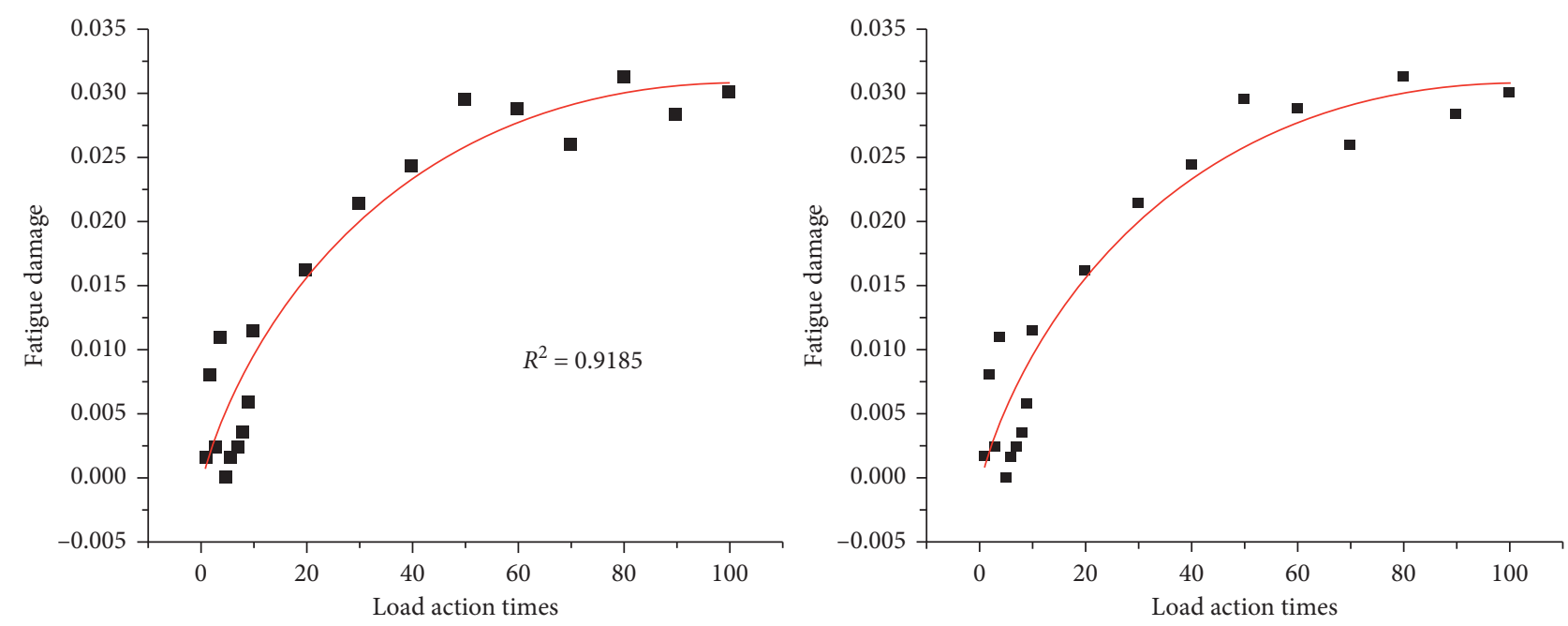

(a)

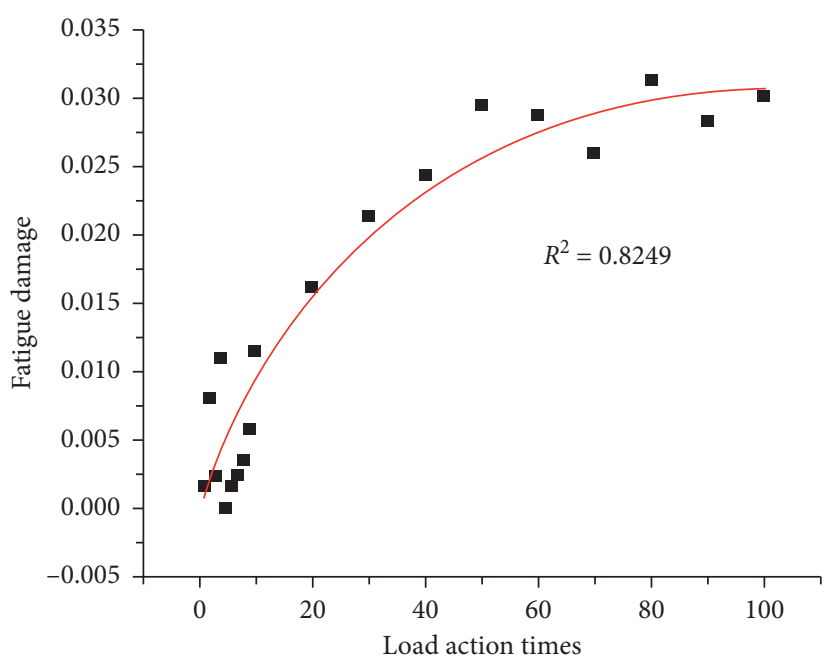

(b)

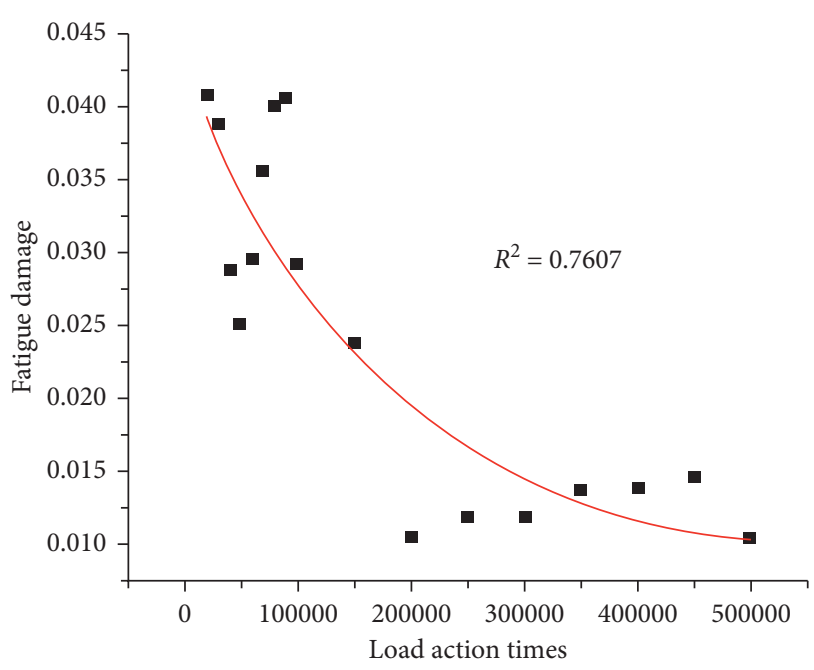

(c)

Figure 2: Accumulation of fatigue damage at each stage of $0.3 \mathrm{~g} / \mathrm{cm}^{3}$ polymer at a stress ratio of 0.7. (a) The first stage of fatigue damage of $0.3 \mathrm{~g} / \mathrm{cm}^{3}$ polymer under 0.7 stress level. (b) The second stage of fatigue damage of $0.3 \mathrm{~g} / \mathrm{cm}^{3}$ polymer under 0.7 stress level. (c) The third stage of fatigue damage of $0.3 \mathrm{~g} / \mathrm{cm}^{3}$ polymer under 0.7 stress level.

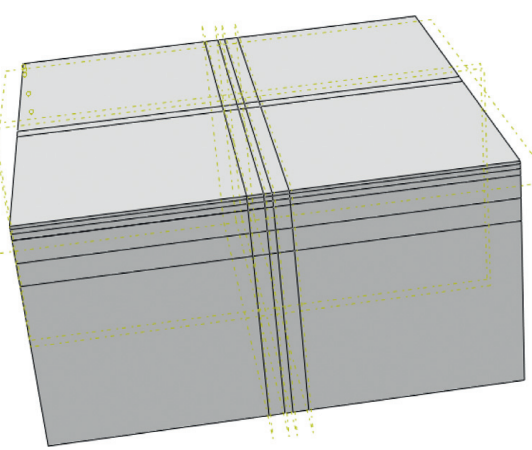

FIGURE 3: Overall structure diagram of semirigid base asphalt pavement.

A void area of size $50 \mathrm{~cm} \times 20 \mathrm{~cm} \times 0.5 \mathrm{~cm}$ is set in the middle of the bottom of the base layer, as shown in Figure 4.
The parameters of the semirigid base asphalt pavement structure materials and polymer grouting materials are listed in Table 3 [25]. 


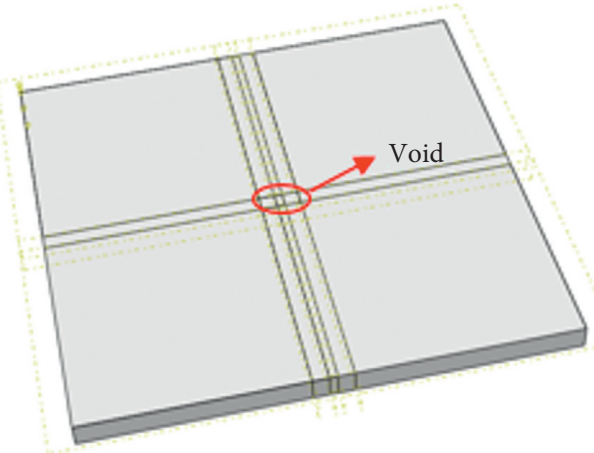

Figure 4: Layout of void area at bottom of base layer.

TABLE 3: Road structure and related parameters of polymer grouting materials.

\begin{tabular}{|c|c|c|c|c|c|}
\hline Structural layer & Material & Thickness $(\mathrm{cm})$ & Modulus of elasticity (MPa) & Poisson's ratio & Density $\left(\mathrm{kg} / \mathrm{m}^{3}\right)$ \\
\hline Upper surface & SMA-13 & 4 & 1400 & 0.35 & 2400 \\
\hline Middle surface & AC-20 & 6 & 1200 & 0.30 & 2400 \\
\hline Under surface & AC-25 & 8 & 1000 & 0.30 & 2400 \\
\hline Base & Cement-stabilized macadam & 30 & 1500 & 0.25 & 2300 \\
\hline Subbase & Cement-stabilized gravel & 30 & 1300 & 0.30 & 1800 \\
\hline Subgrade & Compacted soil & - & 50 & 0.4 & 1920 \\
\hline- & Polymer & 0.5 & 80 & 0.4 & 300 \\
\hline
\end{tabular}

(3) Model boundary conditions and mesh division

The bottom of the model is completely fixed. The left and right sides of the model limit the displacement in the $Z$ direction and the rotation in the $X Y$ direction, and the front and rear sides limit the displacement in the $X$ direction and the rotation in the $Y Z$ direction. Contact surfaces between the surface layer and the base layer and between the base layer and the base layer are established. It is assumed that the two contact surfaces will not be separated and are in a bound state to ensure the continuous transmission of their vertical stress and displacement, as shown in Figure 5.

In the dynamic response analysis, the model uses a $0.1 \mathrm{~m} \times 0.1 \mathrm{~m}$ grid division, and the semirigid base asphalt pavement structure and the polymer material model use C3D8R hexahedral-reduced integral units.

(4) Cyclic traffic load setting

In this study, the vehicle wheel load is simplified as a double rectangular vertical uniform load, and the rectangular size is $0.2 \mathrm{~m} \times 0.167 \mathrm{~m}$. The load surface is a load moving belt based on a single-axle twowheel group. With reference to the standard wheel diameter of $21.3 \mathrm{~cm}$, the center distance between the two wheels is $31.9 \mathrm{~cm}$, and the two-wheel track of the load moving belt is set as $20 \mathrm{~cm}$. The wheel track distance is $10 \mathrm{~cm}$. The traffic load is directly applied to the vacant area, and FORTRAN programming is used to compile subroutines to realize the cyclic movement of the load. The speed of the vehicle load is set as $6 \mathrm{~m} / \mathrm{s}$. A schematic of the traffic load action area is shown in Figure 6.

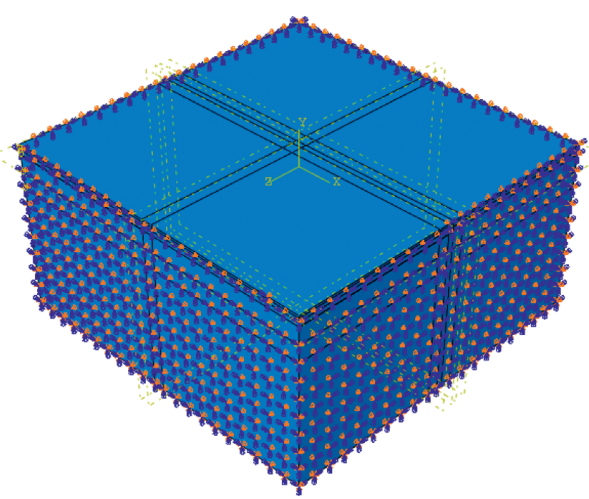

FIGURE 5: Boundary condition setting diagram of pavement structure model.

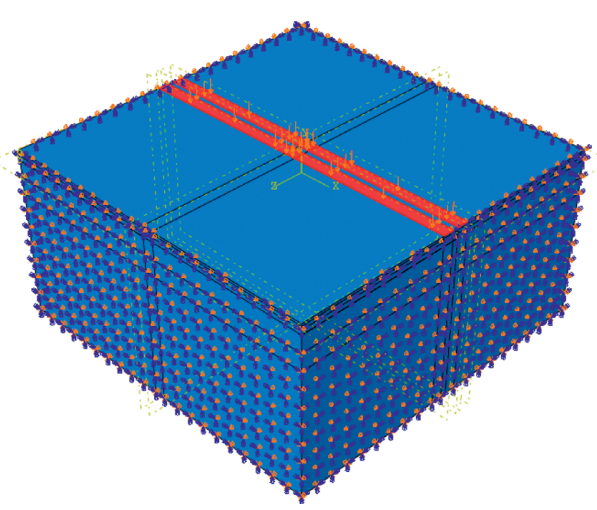

Figure 6: Schematic of traffic load action area. 
3.2. Indoor Fatigue Test. In order to verify the accuracy and rationality of FEM, this paper has produced the semirigid base asphalt pavement structure model specimens under three working conditions: complete, voided, and polymer grouting repair. The servohydraulic fatigue test system is used for cyclic compression fatigue test operation, by collecting the number of load actions under fatigue failure of each working condition and the mechanical response change data under repeated loads and comparing and analyzing the fatigue damage evolution law of the three test conditions.

3.2.1. Production of Model Specimens. Considering the limitations of actual pavement structures and the indoor fatigue test conditions, this study uses semirigid base asphalt pavement structure model specimens to simplify the SMA13 supper layer, AC-20 lower layer, cement-stabilized macadam base, and cement-stabilized macadam base. The four parts have thicknesses of $5 \mathrm{~cm}, 5 \mathrm{~cm}, 10 \mathrm{~cm}$, and $10 \mathrm{~cm}$, respectively.

(1) Fabrication of test piece of asphalt surface model Asphalt surface course model specimens are formed of rut plates. The dimensions of the rut plates are $300 \mathrm{~mm} \times 300 \mathrm{~mm} \times 50 \mathrm{~mm}$. Asphalt, SBS-modified asphalt, and 70\# ordinary asphalt are used. The rut plate mold and the rut plate rolling machine are as shown in Figure 7.

The gradation of the SMA-13 asphalt concrete aggregate is summarized in Table 4.

The SMA-13 asphalt concrete production mix ratio is 0-0.6 mm mineral powder : $0-3 \mathrm{~mm}$ gravel : $3-5 \mathrm{~mm}$ gravel : $5-10 \mathrm{~mm}$ gravel (basalt): $10-15 \mathrm{~mm}$ gravel (basalt) $=11 \%: 11 \%: 5 \%: 30 \%: 43 \%$. The best oilstone ratio is $6 \%$; the amount of lignin fiber is $0.35 \%$ of the total mineral aggregate. The relative density of the asphalt mixture gross volume is $2.457 \mathrm{~g} / \mathrm{cm}^{3}$, and the porosity is $4 \%$.

The grading of the AC-20 asphalt concrete aggregate is summarized in Table 5.

The AC-20 asphalt concrete production mix ratio is 15-20 mm gravel:10-15 mm gravel:5-10 mm gravel : $3-5 \mathrm{~mm}$ gravel: stone powder $=6 \%: 29 \%$ : $20 \%: 14 \%: 31 \%$. The best oil-stone ratio is $4.7 \%$, the relative density of the asphalt mixture gross volume is $2.431 \mathrm{~g} / \mathrm{cm}^{3}$, and the porosity is $4.5 \%$.

After producing the rut plate test piece, the rut board is cut into a small test piece of $300 \mathrm{~mm} \times 100 \mathrm{~mm} \times 50 \mathrm{~mm}$, as shown in Figure 8 .

(2) Production of model specimens of cement-stabilized macadam base course

The middle beam mold is used to form the cementstabilized crushed stone semirigid base course specimen, of size $100 \mathrm{~mm} \times 100 \mathrm{~mm} \times 400 \mathrm{~mm}$, as shown in Figure 9.

The gradation of the cement-stabilized crushed stone is provided in Table 6.
The production mix ratio of the cement-stabilized crushed stone semirigid base is $20-30 \mathrm{~mm}$ crushed stone : $10-20 \mathrm{~mm}$ crushed stone : $5-10 \mathrm{~mm}$ crushed stone : $0-5 \mathrm{~mm}$ crushed stone $=27 \%: 23 \%: 17 \%$ : $33 \%$. The cement content is $5 \%$, the cement strength is 32.5 , the best water content is $5.5 \%$, and the maximum dry density is $2.33 \mathrm{~g} / \mathrm{cm}^{3}$.

After the static pressure test piece is formed, it is cured under standard conditions for three months. The test piece is as shown in Figure 10.

(3) Composition of the pavement structure model

This study uses a $5 \mathrm{~cm}$ SMA-13, $5 \mathrm{~cm}$ AC-20, $10 \mathrm{~cm}$ cement-stabilized macadam, and $10 \mathrm{~cm}$ cementstabilized macadam as the upper surface, under surface, base layer, and subbase layer, respectively, to simulate the semirigid base asphalt pavement structure. Between the upper and under surfaces, petroleum asphalt is used as the adhesive layer to bond the two layers into a whole. A void area is set at the bottom of the base layer, and the void size is set as $10 \mathrm{~cm} \times 5 \mathrm{~cm} \times 3 \mathrm{~cm}$. It is shown in Figure 11 .

3.2.2. Test Process. In this study, the repeated compression fatigue test method under a controlled load mode is used for testing. The test instrument is MTS- $250 \mathrm{kN}$ (servo hydraulic fatigue testing machine), the stress load is $1.2 \mathrm{MPa}$, the load frequency is $10 \mathrm{~Hz}$, and the minimum load $P_{\min }$ of the sine wave load is set to $10 \%$ of the maximum load $P_{\max }$. The test instrument is shown in Figure 12.

The basic process of the test is as follows:

(1) The layout of the sensor is as follows. The strain sensor is set directly under the load; to the bottom of the base layer, two resistance strain gauges are attached. On the top of both the base layer and the fixture below the base layer, thin-film pressure sensors are fixed. The sensor layout diagram is shown in Figure 13, where the yellow box represents the empty area, a blue triangle symbol denotes the location of a resistance strain gauge, and the blue circle symbol represents the location of a pressure sensor.

(2) Repeated fatigue compression operations are performed on the three structural model specimens of the complete pavement structure, voiding, and polymer grouting repair, respectively, as shown in Figure 14.

(3) The number of load actions and the mechanical response data of the pavement structure are detected, extracted, and analyzed for the fatigue failure under each working condition, and the results are compared to the numerical simulation fatigue damage evolution.

\section{Result Analysis}

\subsection{Analysis of Calculation Results}

(1) Comparative analysis of dynamic response of pavement structure models under three working conditions 


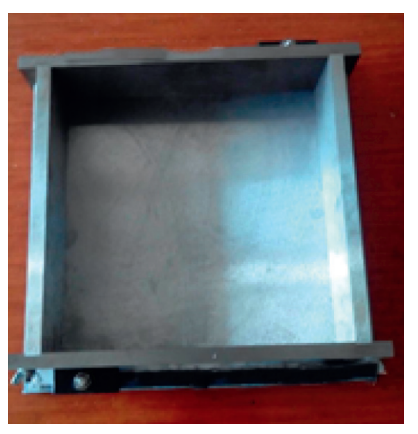

(a)

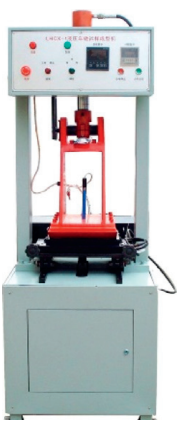

(b)

Figure 7: (a) Rutting plate mold and (b) rutting plate rolling machine.

TABLE 4: SMA-13 asphalt concrete gradation.

\begin{tabular}{lccccccc}
\hline Mesh size $(\mathrm{mm})$ & 19 & 12.5 & 9.5 & 4.75 & 2.36 & 0.3 & 0.075 \\
\hline Passing rate & 100 & $85-100$ & $50-75$ & $20-28$ & $16-14$ & $10-12$ & $8-12$ \\
\hline
\end{tabular}

TABle 5: AC-20 asphalt concrete gradation.

\begin{tabular}{|c|c|c|c|c|c|c|c|c|c|c|c|c|}
\hline Mesh size $(\mathrm{mm})$ & 26.5 & 19 & 16 & 13.2 & 9.5 & 4.95 & 2.36 & 1.18 & 0.6 & 0.3 & 0.15 & 0.075 \\
\hline Passing rate & 100 & 95.1 & 87.6 & 73.3 & 59.6 & 37.8 & 26.1 & 19.1 & 17.1 & 9.2 & 6.2 & 3.6 \\
\hline
\end{tabular}

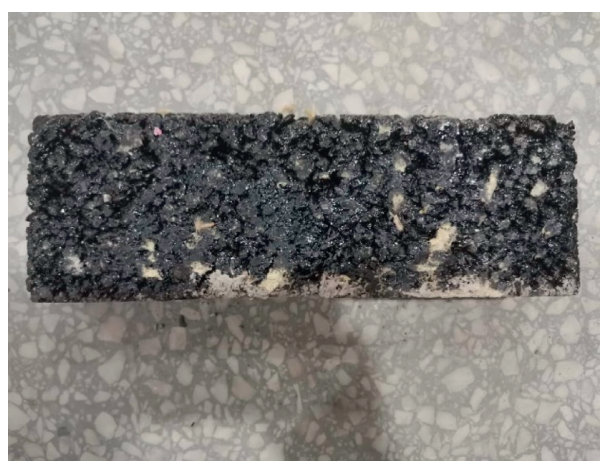

Figure 8: Specimen after cutting rut plate.

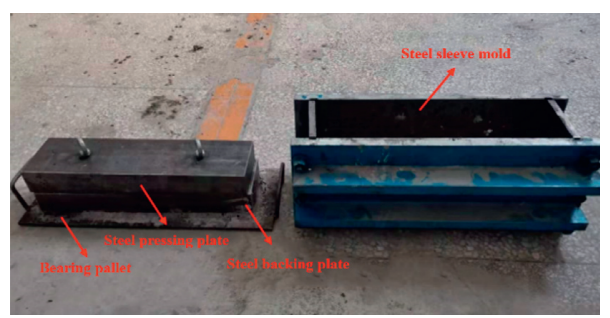

FIGURE 9: Cement-stabilized crushed stone beam mold.

TABle 6: The gradation of cement-stabilized crushed stone.

\begin{tabular}{lccccccccccccc}
\hline Mesh size $(\mathrm{mm})$ & 31.5 & 26.5 & 19 & 16 & 13.2 & 9.5 & 4.95 & 2.36 & 1.18 & 0.6 & 0.3 & 0.15 & 0.075 \\
\hline Passing rate & 100 & 95 & 73 & 67 & 63 & 50 & 33 & 20 & 13 & 9 & 5 & 4 & 2 \\
\hline
\end{tabular}




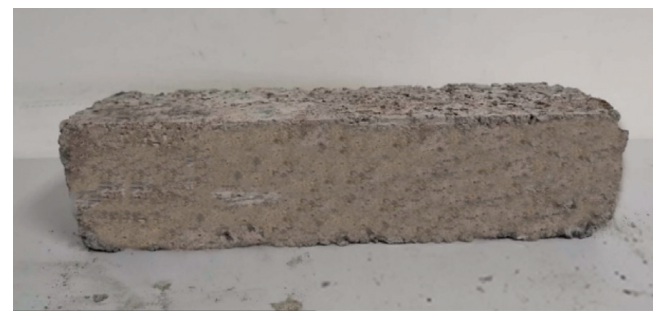

Figure 10: Cement-stabilized crushed stone molding test piece.

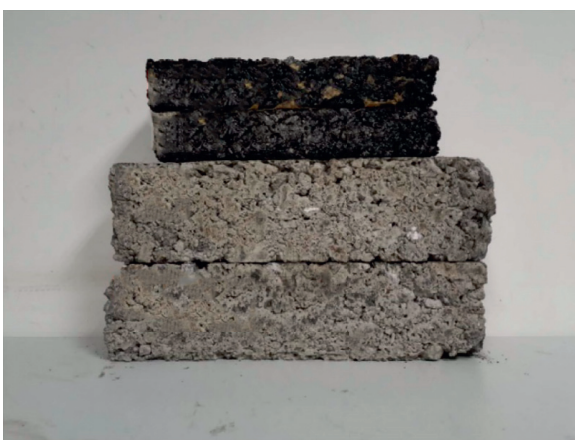

(a)

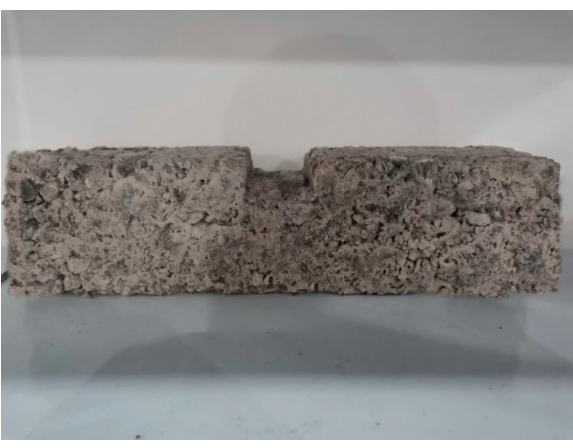

(b)

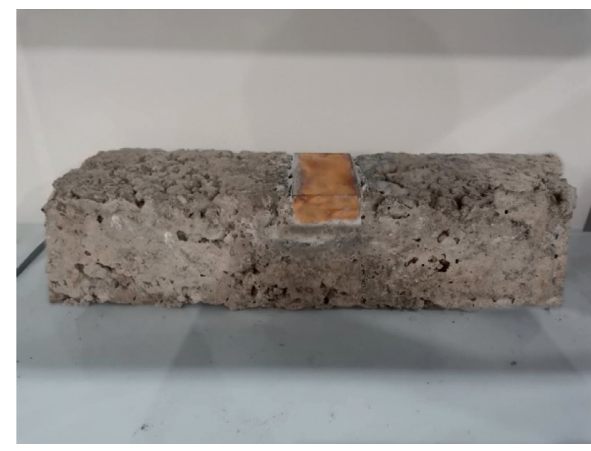

(c)

Figure 11: Different working conditions for structural layer model specimens. (a) Complete model test piece of pavement structure. (b) Model test piece of structural layer void. (c) Structural layer repair model test piece.

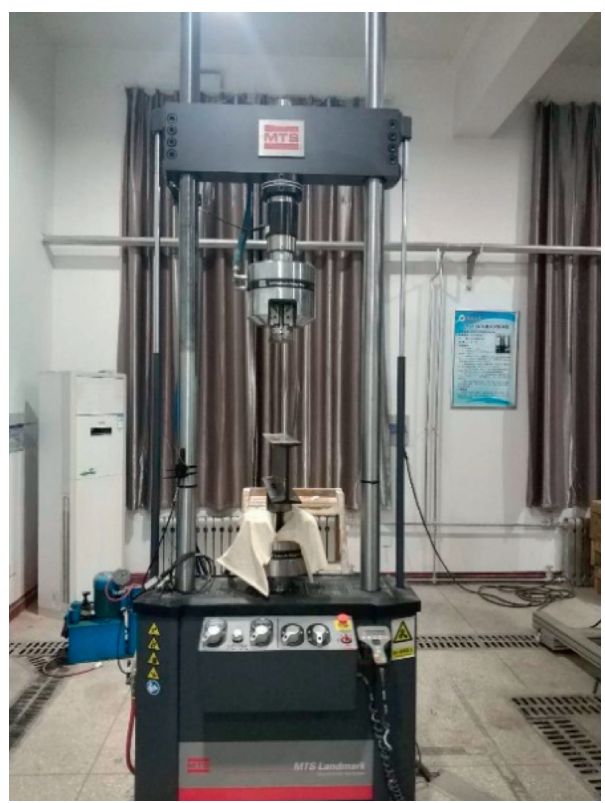

FiguRE 12: MTS-250 kN (servo hydraulic fatigue testing machine). 


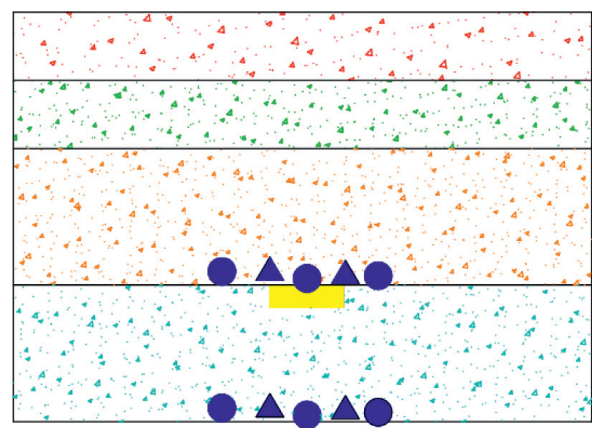

FIGURE 13: Schematic diagram of layout.

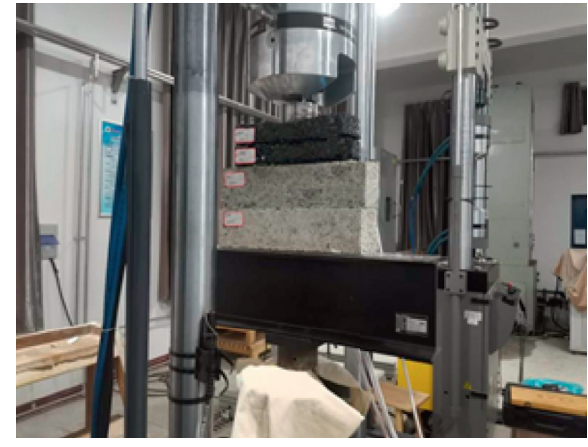

(a)

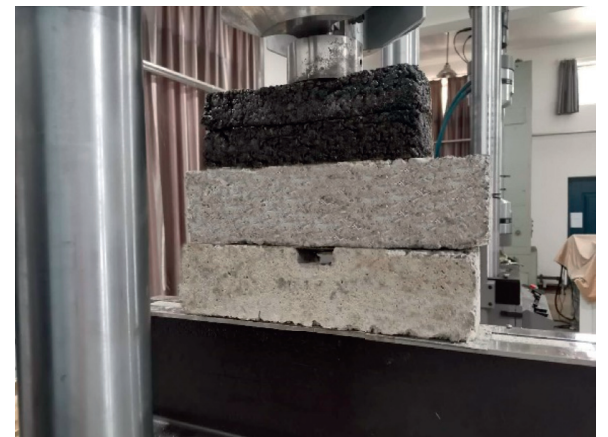

(b)

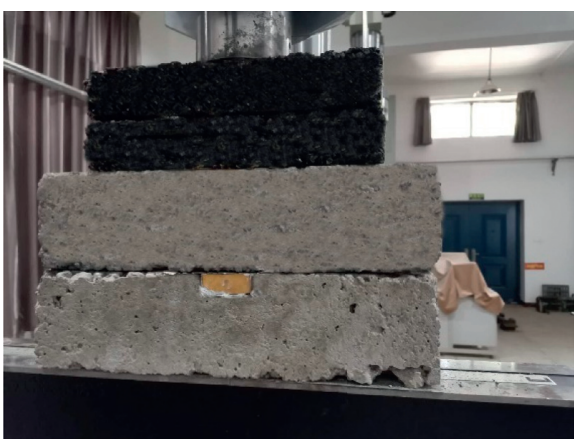

(c)

Figure 14: Repeated compression fatigue test diagram of structural model. (a) Compression fatigue test of complete structure model. (b) Compression fatigue test diagram of void structure model. (c) Compression fatigue test diagram of repaired structure model.

A standard load of $0.7 \mathrm{MPa}$ was applied to the vacant area for a single movement, and three working conditions, complete base course, vacant, and polymer grouting repairs, were compared and analyzed. This study selects the three working conditions when the moving load moves to the top surface of the void to draw the Mises stress and vertical displacement comparison diagrams, as shown in Figures 15 and 16, respectively.

It can be seen from Figure 15 that the Mises stress in the void position of the pavement structure base layer is $217 \mathrm{kPa}$ and that stress concentration occurs. After the polymer grouting repair, the Mises stress at the void position is reduced to $176 \mathrm{kPa}$.
Compared to the void condition, after the repair, the Mises stress is reduced by $69 \%$, which proves that polymer grouting is effective in repairing the void in the base layer.

It can be seen from Figure 16 that the vertical displacement of the empty position of the pavement structure under the empty condition is $480 \mu \mathrm{m}$, which after the polymer grouting repair is $319 \mu \mathrm{m}$. Compared to the vacant condition, the vertical displacement after the repair is reduced by $61 \%$, which proves that polymer grouting repair can significantly reduce the vertical displacement of the semirigid base asphalt pavement. 


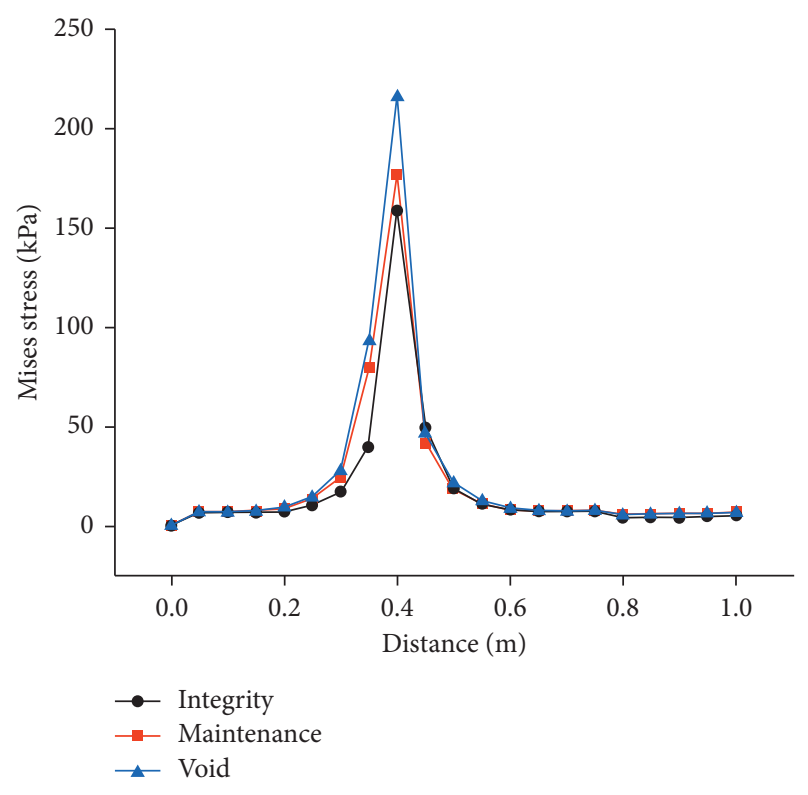

Figure 15: Mises stress comparison diagram of three working conditions.

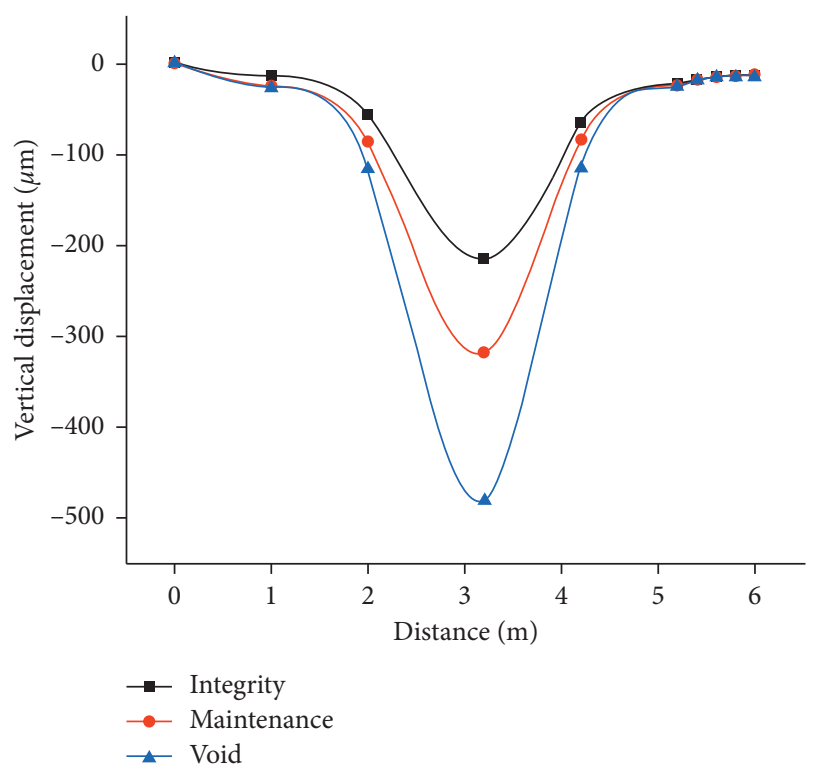

Figure 16: Comparison analysis diagram of vertical displacement under three working conditions.

(2) Comparative analysis of distribution law of fatigue damage field of pavement structure model under three conditions

This study selects a 1.2 MPa cyclic load to analyze the fatigue damage field distribution law of the semirigid base asphalt pavement structure. In view of the three working conditions of the pavement structure base course integrity, voiding, and polymer grouting repair, a pavement structure with repeated loads of 4.65 million times is selected as the research object (when the repeated load is 4.65 million times, the fatigue damage basically reaches
$0.5)$. The element integration point where the fatigue damage variable $D$ first accumulates to 0.5 is selected as the origin to establish a three-dimensional coordinate system. The vehicle travel direction is the $X$ direction, the road plane perpendicular to the vehicle travel direction is the $Y$ direction, and the vertical direction is the $Z$ direction. The distribution diagrams of the fatigue damage field on the $x$-, $y$-, and $z$-axes of the three working conditions of the road structure model are shown in Figures 17-19, respectively.

From Figure 17, in the $X$ direction, when the road bears 4.65 million repeated loads, the fatigue damage $D$ at the bottom of the base layer directly above the void area is the highest. At the bottom of the base layer $0.5 \mathrm{~m}$ away from the void area, the three types of works of the fatigue damage of the condition model are not much different, indicating that the void disease has a limited impact on the overall road. After the polymer grouting repair, the fatigue damage $D$ in the $X$ direction is significantly reduced, indicating that the polymer grouting has voided the bottom of the semirigid base asphalt pavement base. The long-term repair effect is remarkable.

It can be seen from Figure 18 that, in the $Y$ direction, when the road is subjected to 4.65 million repetitive loads, the fatigue damage $D$ presents a single-peak curve, and $D$ is the highest at the bottom of the base layer directly above the void area. At the center line of the wheel track, the road damage is the most significant, where the load is approximately $0.75 \mathrm{~m}$ on both sides of the load. The impact of the load on the road fatigue damage is reduced; after the polymer grouting repair, the fatigue damage $D$ in the $Y$ direction is significantly reduced, indicating that the polymer grouting affects the base. The long-term repair effect of voiding is remarkable.

It can be seen from Figure 19 that, in the $Z$ direction, when the road bears 4.65 million repeated loads, the fatigue damage $D$ reaches the maximum at the bottom of the base layer and gradually decreases upwards. The fatigue damage $D$ at the bottom of the base layer is relatively significant, and the upward fatigue damage $D$ decreases, being basically reduced to 0 . The impact range of the cyclic load on the road is from the road surface to $0.8 \mathrm{~m}$ below the surface, with a greater impact being on the bottom base layer and above the structural layers of the pavement structure. The $Z$ direction fatigue damage $D$ is noticeable after the polymer grouting repair decreases, indicating that polymer grouting has a significant effect on the long-term repair of the voids at the bottom of the semirigid base asphalt pavement base.

(3) Comparative analysis of cumulative evolution law of fatigue damage of pavement structure models under three conditions 


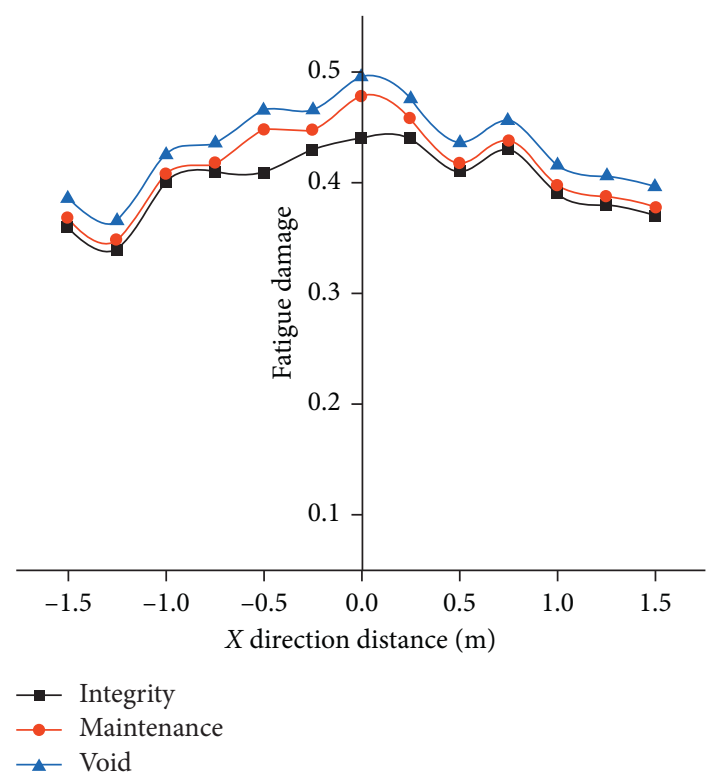

FIgURE 17: Fatigue damage distribution in $X$ direction at bottom of base under three conditions.

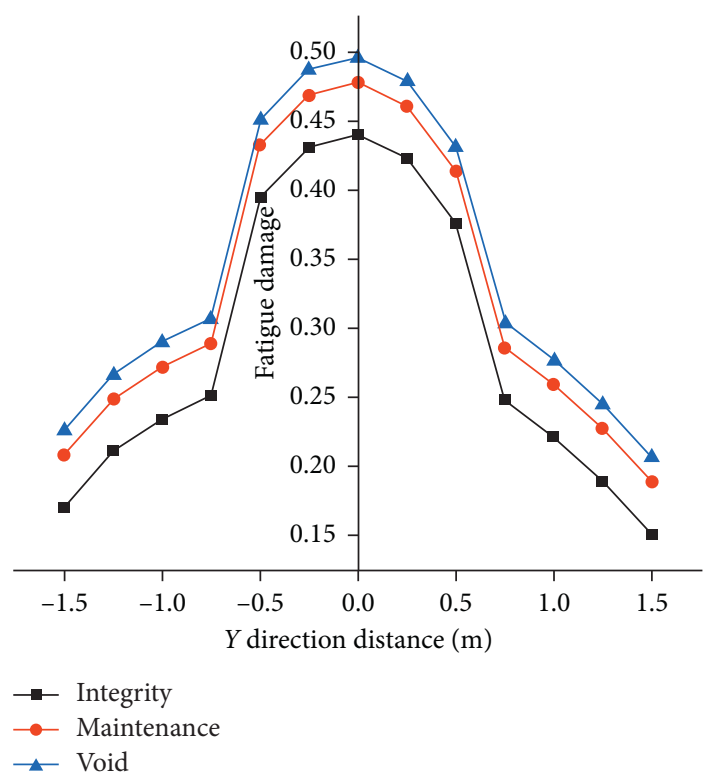

FIgURE 18: Fatigue damage distribution in $Y$ direction at bottom of base under three conditions.

Under the action of the traffic cyclic load, a semirigid base asphalt pavement structure will experience accumulation of fatigue damage. As the number of loads continues to increase, the fatigue damage will develop until macro cracks appear. In this study, a 1.2 MPa cyclic load is used to analyze the cumulative evolution of the fatigue damage under three working conditions: bottom of the pavement structure base is completed, voided, and polymer grouting repaired. The fatigue damage degree under the three working conditions varies with the number of loads, as shown in Figure 20.

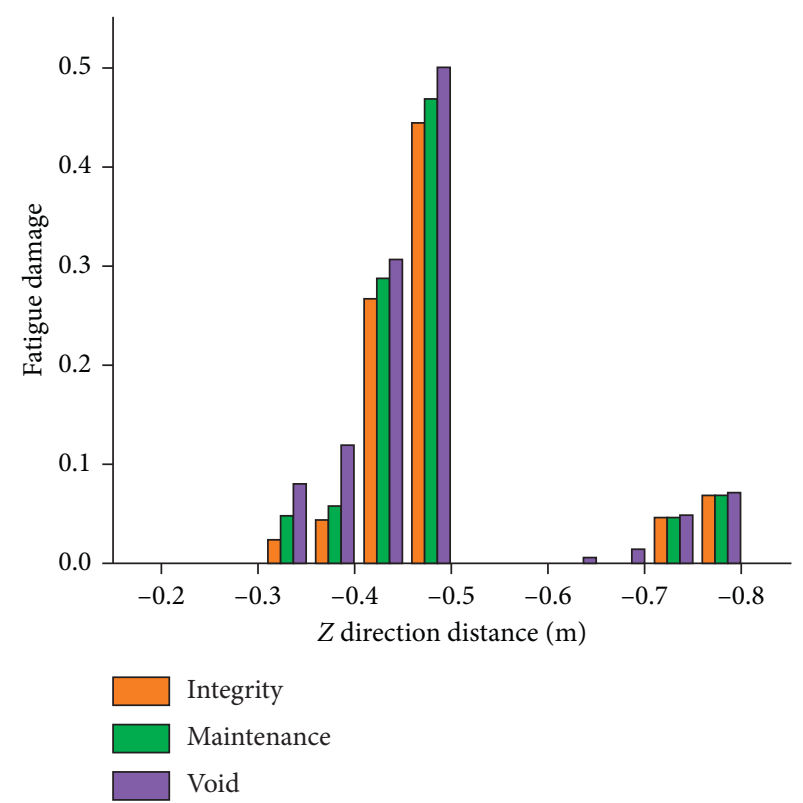

FIgURE 19: Fatigue damage distribution in $Z$ direction corresponding to three working conditions.

It can be seen from Figure 20 that, under the action of a 1.2 MPa cyclic load, when the number of load actions is 5,00,000, the fatigue damage degree of the hollow pavement structure model reaches 0.2813. When the number of load actions is increased from $5,00,000$ to 2 million, the fatigue damage $D$ is increased to 0.423 ; when it is increased from 2 million to 5 million, the fatigue damage variable $D$ reaches 0.5223 . With the increase in the number of loads, the development rate of the fatigue damage in the void position of the pavement structure decreases. After the polymer grouting repair, when the number of loads is $5,00,000$, the growth rate of the fatigue damage $D$ decreases, and the cumulative development of fatigue damage is relatively slow. When the number of load actions reaches 5 million, the cumulative fatigue damage of the pavement structure is 0.3691 , which is reduced by $29 \%$ compared to that of the hollow structure, which significantly reduces the degree of fatigue damage. This proves that the polymer grouting has a good repair effect of the semirigid base layer hollow disease effect.

To analyze the impact of different loads on the fatigue damage of the semirigid base asphalt pavement structure, this study uses $1.0 \mathrm{MPa}$ and $1.4 \mathrm{MPa}$ tire ground pressures to act under the three working conditions, as shown in Figures 21 and 22, respectively.

It can be seen from Figures 20-22 that the greater the tire ground pressure, the fewer the number of load actions required for the fatigue damage factor of the pavement structure to reach 0.5 . When the tire ground pressure is $1.4 \mathrm{MPa}$, the cyclic load acts $1,00,000$ times. Subsequently, the fatigue damage of the intact pavement structure exceeds that of the 


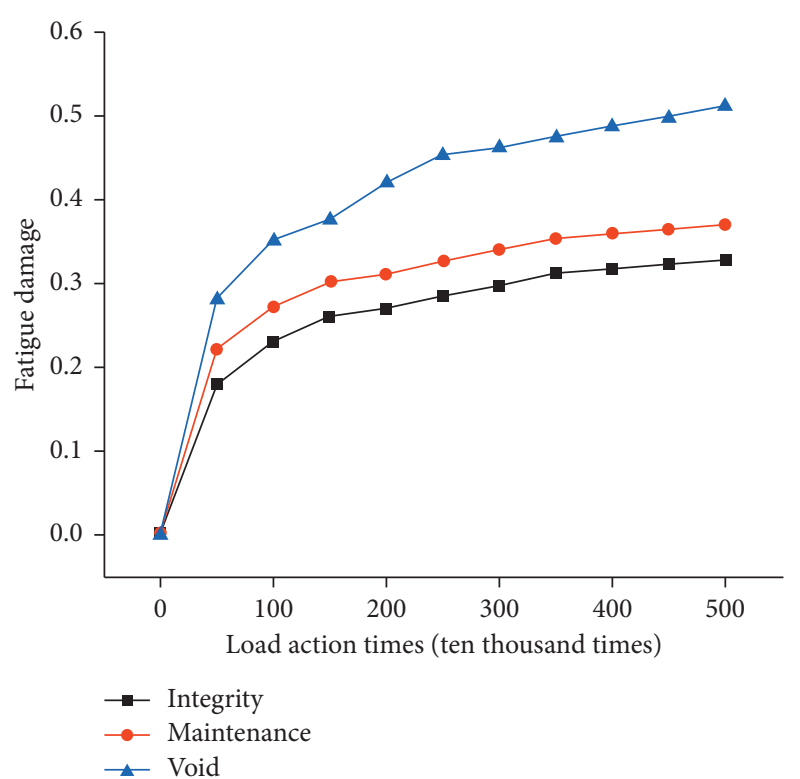

FIgURE 20: Cumulative evolution of fatigue damage under three working conditions under $1.2 \mathrm{MPa}$ tire pressure.

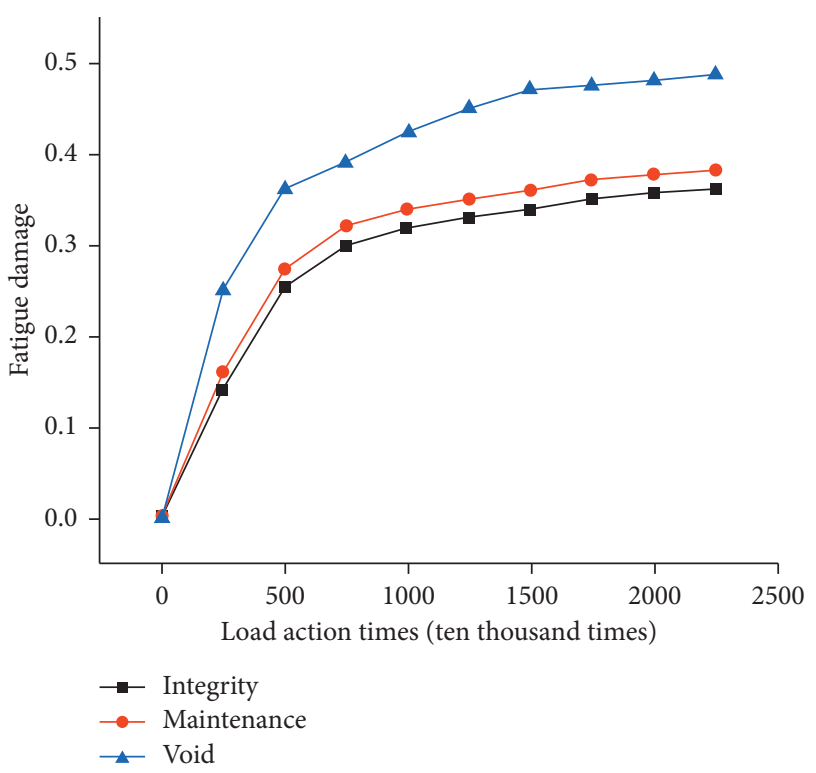

Figure 21: Cumulative evolution of fatigue damage under three working conditions under 1.0 MPa tire pressure.

polymer grouting to repair the pavement structure. This is mainly because the polymer material fatigue damage model is reoriented after the repeated compression of the polyurethane molecular chain under a low-stress ratio, resulting in crystallization and cyclic hardening.

4.2. Analysis of Test Results. The number of load actions required for the three pavement structure model working conditions to reach failure is shown in Figure 23.

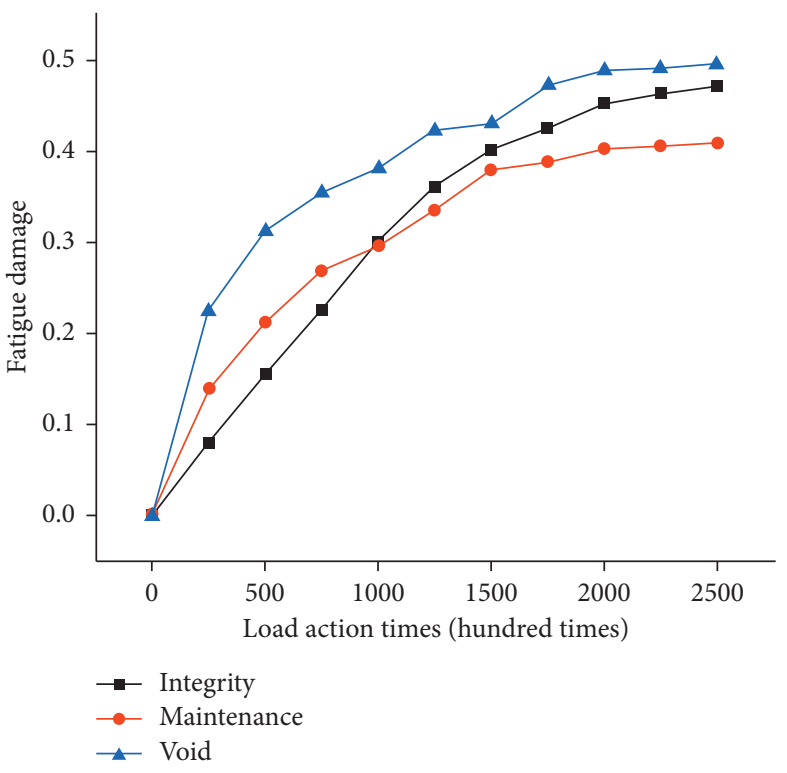

FIgURE 22: Cumulative evolution of fatigue damage under three working conditions under $1.4 \mathrm{MPa}$ tire pressure.

It can be seen from Figure 23 that the number of load actions required for the complete, repair, and void structure models to reach failure is 269416,244318 , and 117215 , respectively. The formula for calculating the repair effect $N$ is $\left(N_{r}-N_{v}\right) /\left(N_{c}-N_{v}\right)$, and the long-term use performance repair effect of the pavement structure model can reach $83.51 \%$.

Based on the strain value extracted from the test and the corresponding load action times, the tensile stress values of the same load acting under the three working conditions corresponding to the same position are not much different. Moreover, the relationship between the fatigue damage variable $D$ and the load action times can be obtained. The bottom is the research object, and the cumulative evolution law of the fatigue damage under the three working conditions is compared and analyzed. The specific analysis is as follows.

It can be seen from Figure 24 that when the number of load actions is less than 100, the fatigue damage value does not change much. When the number of load actions is greater than 100, the more the number of load actions, the greater the fatigue damage value of the pavement structure, showing a two-stage change. The fatigue damage value of the pavement structure base layer has the fastest increase in the empty condition, and the number of load actions is the least at the end of the second stage. The growth rate of the fatigue damage value of the polymer-repaired pavement structure is significantly reduced compared to that of the empty pavement structure. At the end of the second stage, the number of load actions is basically the same as that of the complete pavement structure. Similar to the numerical simulation results, at the same location, under the comparison of the three working conditions, it is reflected in the fatigue damage accumulation level. Compared with the polymer grouting condition, the void damage accumulation is slower. The cumulative evolution trend of the fatigue damage in the 


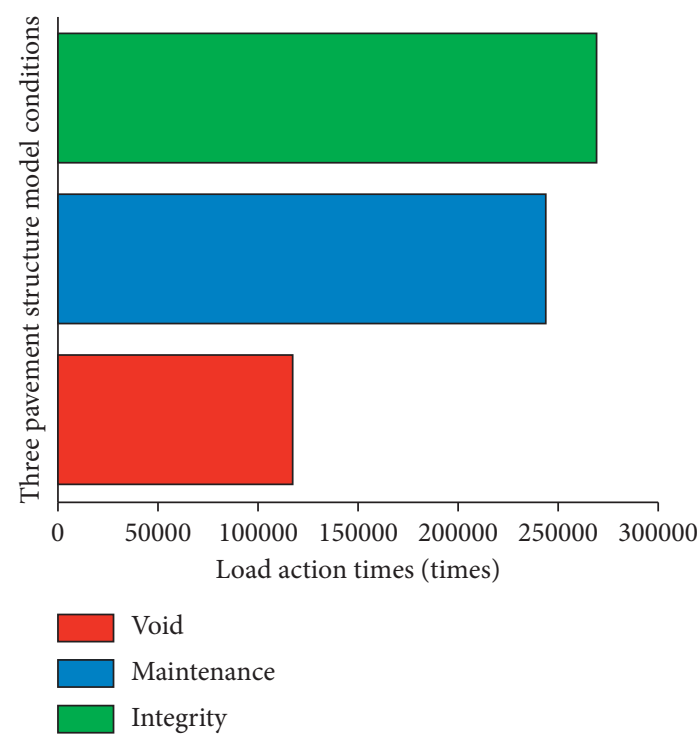

FIgUre 23: Compression fatigue failure load action times of three pavement structure models.

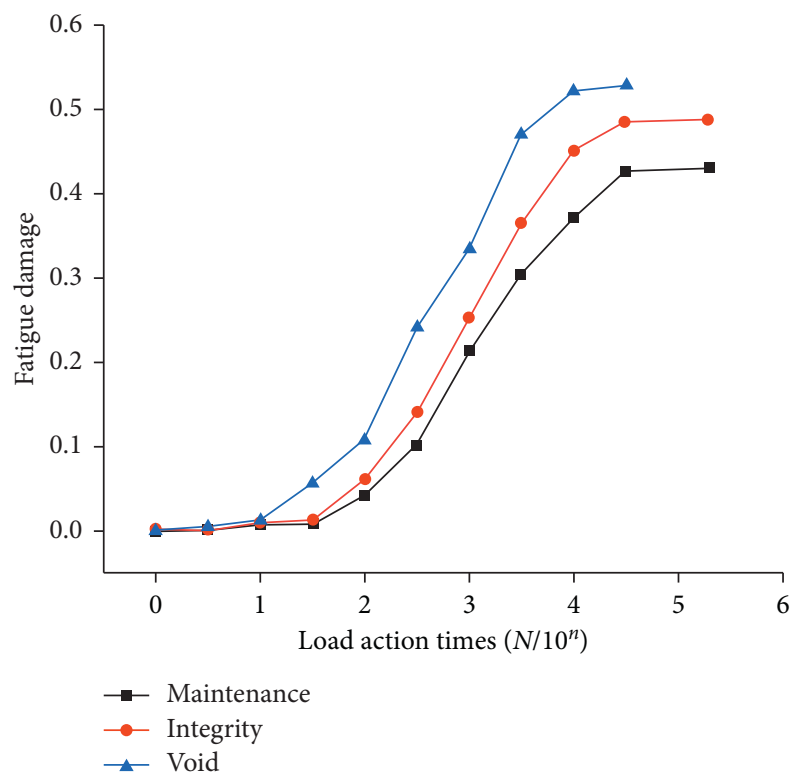

FIgURE 24: Cumulative evolution of fatigue damage under three basic working conditions.

three working conditions is basically consistent with the numerical simulation results, which verifies the rationality of the numerical model.

\section{Conclusion}

This study uses the finite element method to establish a three-dimensional numerical model of a semirigid base asphalt pavement structure and compares and analyzes the mechanical response and fatigue damage evolution law of the pavement before and after vacant polymer repair. The model is verified by indoor fatigue tests. The following conclusions are drawn:

(1) The simplified Chaboche nonlinear fatigue damage model is revised, and a two-stage fatigue damage model suitable for semirigid base materials is established. The cyclic compression fatigue test data of polymer grouting materials are subjected to regression analysis and shown to be suitable for high $D-N$ damage evolution model of polymer materials.

(2) Under the action of a 0.7 MPa standard load, the vertical displacement and Mises stress value of the vacant position of the vacant polymer-repaired pavement structure base layer are reduced by $61 \%$ and $69 \%$, respectively. This indicates that polymer grouting technology repairs the semirigid base layer, and the effect of voiding disease on the asphalt pavement base is good.

(3) Under a 1.2 MPa cyclic load, the fatigue damage factor increases with the increase in the number of repeated loads, but the development rate of fatigue damage of pavement structure is decreasing. When the repeated loads increase from 5,00,000 times to 5 million times, the fatigue damage factor of the pavement structure is 0.5223 when the base layer of the pavement structure is empty. The fatigue damage factor of the pavement structure after the polymer repair is 0.3691 , which is $29 \%$ lower than that of the empty structure. Prove that the polymer grouting repair method can effectively reduce the degree of fatigue damage.

(4) Under different the tire contact pressure, the fatigue damage of the pavement structure after the polymer repair is lower than that of the empty pavement structure. And the greater the tire contact pressure, the fewer the number of load actions required for the fatigue damage factor of the pavement structure to reach 0.5 and the shorter the time for the fatigue failure of the pavement structure. Under the action of 1.4 MPa cyclic load, the accumulation of fatigue damage of polymer-repaired pavement structure is smaller than that of complete pavement structure.

(5) With the increase of the number of fatigue test loads, the development rate of the fatigue damage degree of the three working conditions at the bottom of the base layer basically shows a downward trend. Moreover, at the same location, the accumulation of fatigue damage under polymer grouting conditions is slower than that under void conditions. It can be seen that the cumulative evolution trend of fatigue damage is basically consistent with the numerical simulation results, which verifies the rationality of the numerical model.

\section{Data Availability}

The data used to support the findings of this study are included within the article.

\section{Conflicts of Interest}

The authors declare that they have no conflicts of interest. 


\section{Acknowledgments}

The authors acknowledge the support received from the National Key Research and Development Plan (Grant no. 2018YFB1600200), the National Natural Science Foundation of China (Grant nos. 51878624 and 51878622), Major Scientific and Technological Special Project in Henan (Grant no. 181100310400), Henan Science Fund for Distinguished Young Scholars (Grant no. 202300410354), Natural Science Foundation of Henan Province (Grant no. 202300410746), the Program for Science and Technology Innovation Talents in Universities of Henan Province (Grant no. 19HASTIT041), and Key Research Projects of Higher Education in Henan Province (Grant no. 18A580001).

\section{References}

[1] X. Wang, X. Ma, and D. Baraldi, "Responses of semi-rigid base asphalt pavement with interlayer contact bonding model," Advances in Civil Engineering, vol. 2020, Article ID 8841139, 13 pages, 2020.

[2] X. Yan, L. Chen, Q. You, and Q. Fu, "Experimental analysis of thermal conductivity of semi-rigid base asphalt pavement," Road Materials and Pavement Design, vol. 20, no. 5, pp. 1215-1227, 2019.

[3] S. R. Maitra, K. S. Reddy, and L. S. Ramachandra, "Numerical investigation of fatigue characteristics of concrete pavement," International Journal of Fracture, vol. 189, no. 2, pp. 181-193, 2014.

[4] J. Hu, P. Liu, D. Wang, M. Oeser, and Y. Tan, "Investigation on fatigue damage of asphalt mixture with different air-voids using microstructural analysis," Construction and Building Materials, vol. 125, pp. 936-945, 2016.

[5] H. Cheng, L. Sun, L. Liu, and H. Li, "Fatigue characteristics of in-service cold recycling mixture with asphalt emulsion and HMA mixture," Construction and Building Materials, vol. 192, pp. 704-714, 2018.

[6] M. Barman, R. Ghabchi, D. Singh, M. Zaman, and S. Commuri, "An alternative analysis of indirect tensile test results for evaluating fatigue characteristics of asphalt mixes," Construction and Building Materials, vol. 166, pp. 204-213, 2018.

[7] S. Lv, C. Xia, L. You, X. Wang, J. Li, and J. Zheng, "Unified fatigue characteristics model for cement-stabilized macadam under various loading modes," Construction and Building Materials, vol. 223, pp. 775-783, 2019.

[8] J. Zhang, Y. D. Wang, and Y. Su, "Fatigue damage evolution model of asphalt mixture considering influence of loading frequency," Construction and Building Materials, vol. 218, pp. 712-720, 2019.

[9] J. Wei, T. Fu, Y. Meng et al., "Investigating the fatigue characteristics of large stone asphalt mixtures based on the disturbed state concept," Advances in Materials Science and Engineering, vol. 2020, Article ID 3873174, 10 pages, 2020.

[10] Q. Chen, G. Wang, and W. Pan, "Research on relationships among different disease types of cement concrete pavement based on structural formula model," Mathematical Problems in Engineering, vol. 2020, Article ID 9580616, 13 pages, 2020.

[11] C. Guo and F. Wang, "Mechanism study on the constructing of ultra-thin antiseepage wall by polymer injection," Journal of Materials in Civil Engineering, vol. 24, no. 9, pp. 1183-1192, 2012.
[12] M. Shi, F. Wang, and J. Luo, "Compressive strength of polymer grouting material at different temperatures," Journal of Wuhan University of Technology, vol. 25, no. 6, pp. 962-965, 2010.

[13] K. Liu, W. Liang, F. Ren, J. Ren, F. Wang, and H. Ding, "The study on compressive mechanical properties of rigid polyurethane grout materials with different densities," Construction and Building Materials, vol. 206, pp. 270-278, 2019.

[14] A. Bezazi and F. Scarpa, "Tensile fatigue of conventional and negative Poisson's ratio open cell PU foams," International Journal of Fatigue, vol. 31, no. 3, pp. 488-494, 2008.

[15] D. Pulungan, A. Yudhanto, S. Goutham, G. Lubineau, R. Yaldiz, and W. Schijve, "Characterizing and modeling the pressure- and rate-dependent elastic-plastic-damage behavior of polypropylene-based polymers," Polymer Testing, vol. 68, pp. 433-445, 2018.

[16] M. Nazari, R. Ghabchi, and M. Zaman, "Flexural properties of chemically stabilised subgrade in designing semi-rigid pavements," Road Materials and Pavement Design, vol. 20, no. 4, pp. 836-858, 2019.

[17] H. Liu and R. Luo, "Development of failure criterion and fatigue model to characterize the fatigue resistance of asphalt binders under controlled-stress time sweep tests," Materials and Structures, vol. 53, no. 4, pp. 141-149, 2019.

[18] H. Wen, "Use of fracture work density obtained from indirect tensile testing for the mix design and development of a fatigue model," International Journal of Pavement Engineering, vol. 14, no. 6, pp. 561-568, 2013.

[19] J. Füssl and R. Lackner, "Multiscale fatigue model for bituminous mixtures," International Journal of Fatigue, vol. 33, no. 11, pp. 1435-1450, 2011.

[20] I. Farreras-Alcover, M. K. Chryssanthopoulos, and J. E. Andersen, "Data-based models for fatigue reliability of orthotropic steel bridge decks based on temperature, traffic and strain monitoring," International Journal of Fatigue, vol. 95, pp. 104-119, 2017.

[21] X. Gao, Ya Wei, F. Wang et al., "Fatigue performance and microstructure evolution of polyurethane grouting material under cyclic compression loading," Journal of Composite Materials, vol. 34, no. 3, pp. 550-556, 2017.

[22] G. Bosurgi and W. Perlongo, "Numerical analysis of fatigue cracks growth in flexible pavements with the elastoplastic fracture mechanics method," Structure and Infrastructure Engineering, vol. 10, no. 8, pp. 1027-1037, 2014.

[23] F. Homsi, D. Bodin, S. Yotte, D. Breysse, and J. M. Balay, "Fatigue life modelling of asphalt pavements under multipleaxle loadings," Road Materials and Pavement Design, vol. 13, no. 4, pp. 749-768, 2012.

[24] F. Moreno-Navarro, M. Sol-Sánchez, and M. C. RubioGámez, "Exploring the recovery of fatigue damage in bituminous mixtures: the role of healing," Road Materials and Pavement Design, vol. 16, no. 1, pp. 75-89, 2015.

[25] J. Hu, P. Liu, and B. Steinauer, "A study on fatigue damage of asphalt mixture under different compaction using 3Dmicrostructural characteristics," Frontiers of Structural and Civil Engineering, vol. 11, no. 3, pp. 329-337, 2017. 